bility of the bridge when erected would equal that of the best existing structures of that class.

The paper referred to contains six points of objection, which are treated in a general way without attempting a scientific criticism. This is to be regretted considering the importance of the subject. I take each point in succession. With regard to

I. I cannot see an objection to the novelty of a system, if, as $\mathrm{n}$ this case, the conditions are unprecedented, and if the author of the paper himself is compelled to recommend a system of striking novelty.

II. What, may be asked, constitutes the enormity of magnitude of a structural part? Is it the excessive proportion of strain in it arising from its own weight to that arising from other weights and forces? If so, it will be found that this proportion may here be still very small, although it may not be ignored, as sometimes is done.

III. The experimental knowledge hitherto derived from structures with rising degrees of magnitude has not upset the theories used in the calculations of strength. It cannot be asserted that the top flange of a common rolled beam, being a strut, we assume twenty times as long as it is wide, would be under a test load in a safer position against buckling than the top flange of the Ohio girder bridge, which is 510 feet long and 20 feet wide, or the bottom flange of the Forth Bridge, which is 675 feet long and from 32 to 120 feet wide.

IV. We constantly rely on the strength of long struts; they exist in all girders, and many of them are of the same importance for the strength of the girders as the links for the strength of a chain. The theory of their strength, imperfect as it is, is applicable to all with a fair amount of truth, and there is no reason why it should not be applied equally to the struts in the Forth Bridge.

V. Assuming that the dangers from wind-pressure during the erection do not concern us here, it would be interesting to hear from the author which parts of the erected bridge wonld probably give way first, and whether this would take place by crushing, shearing, twisting, or pulling actions. The leverage offered to wind by the long brackets would come into question only when the pressure is different on the two sides of a pier. The difference would produce a twisting action, which would exist in the central pier, but which could be obviated in the two side piers. The resisting leverage of the central pier is 270 feet, or about two-thirds of the acting leverage. Approximately the same proportion obtains with regard to the stability against tilting under uniform wind-pressure, while in the case of the Tay Bridge the proportion was less than one-third.

VI. It is highly improbable that Mr. Baker should not have calculated his struts; in his book on the strength of beams, columns, and arches, he gives a very intelligible deduction of the theory of long struts, which, although elementary anil not so elegant as that by the author, seems original. I have found deductions of that kind in most English text books, while in books of foreign origin generally the equation of the line of flexure is taken as the starting point. Its approximate form is-

$$
-\frac{M}{E I}=\frac{\mathbf{r}}{\rho}=\frac{d^{2} y}{d x^{2}}
$$

$M$ being the bending moment at any point, $E$ the modulus of elasticity, $I$ the moment of inertia of the section of the strut, and $\rho$ the radius of curvature. The integration gives the limiting weight $W$ acting endways upon a long strut, as already Navier stated it,

$$
W=\frac{\pi^{2}}{a^{2}} E I
$$

where $E I=C$ in the Paper. This formula is not applicable to short struts, since $W$ might exceed the crushing strength of the material. The limiting weight $W^{1}$ for short columns is therefore calculated with $W^{x}=f p$, where $f$ is the sectional area and $p$ the pressure on the sectional unit. Unfortunately there exists among theorists a difference of opinion as to the proper value of $p$; some put for it the crushing strength, and others the limit of elasticity, and now and then there are controversies going on about this matter. Meanwhile it is impossible to mark the limit between short and long struts which theoretically exists. Practically, however, the limit is indistinct, and Rankine, Gordon, and others, taking this into consideration, bave put the two formulæ together into one empirical formula for $W^{\prime \prime}$, the limiting weight for struts of any given dimensions.

$$
W^{\prime \prime}=\frac{W^{1}}{\mathbf{I}+\frac{W^{1}}{W}}
$$

This formula embellished with some empirical coefficients gives good results for struts of ordinary proportions, and as the struts in the Forth Bridge seem to bave ordinary proportions, it is quite safe to use it for their calculation. M. AM ENDE

3, Westminster Chambers, Victoria Street, S. W., October 24

HAVING read with interest Sir G. Airy's article on this sub. ject in the last number of NATURE, I am glad to see that it advocates a suspension-bridge in lieu of the proposed structure. It may perhaps interest your readers to give the particulars of the Great International Suspension Bridge over the Niagara River, which supports a carriage-way and a railway-track above.

The length of span between the towers is 800 feet. There are 4 cables, each composed of 3640 wires No. $9={ }^{\prime} 155^{\prime \prime}$ diam., without weld or joint; the cables are $\mathrm{IO}^{\prime \prime}$ in diameter. All tre wires of each cable were separately brought into position, so that each one bears its full share of the tension. When a cable had been thus built up, it was tightly served with soft iron wire to bind the 3640 wires together, and to preserve them from rust.

Since this bridge was built, great improvements have bee! made in the manufacture of wire. Whereas the resistance to tensile stress at the moment of fracture of the best qualities of iron wire, such as that manufactured at Manchester for this bridge, does not much exceed 27 tons per square inch of section, hardened and tempered steel wire can now be made in large quantities and in long lengths with a minimum resistance at the moment of fracture of 90 tons per square inch.

Steel plates, rods, or bars cannot be made in quantity with a higher re:istance than 34 tons, or less than half that of wire. Hardened and tempered steel wire similar to that used in pianos is thus clearly the most suitable material for suspension bridges, and has been recognised as such in America, where it is to be used in the construction of the New York and Brooklyn suspension bridge, the span of which is the same as the proposed Forth Bridge.

Our English railway engineers, however, have not yet recog. nised the great advantages wire possesses over any other form of material such as bars, chains, \&c., for resisting tensile stress, and the further advantages that wire can be tested more easily and made of a more uniform quality.

Some ten years ago I called on Sir T. Bouch, the former Engineer to the Forth Bridge, to point out the advantages of a tempered steel wire suspension bridge over any other form. of structure for the Forth Bridge. The idea was, however, never worked out on paper.

Manchester, October 23

\section{On the Alterations in the Dimensions of the Magnetic Metals by the Act of Magnetisation}

I HAVE read with interest Prof. Barrett's paper in NATURE, vol. xxvi. p. 585. Between his results as to the effect of magnetisation on the dimencions of bars of iron, of steel, and of nickel, and those of Sir William Thomson's experiments ("Electrodynamic Qualities of Metals," Part VII., Phil. Trans. R. S., Part I., 1879) on the effects of stress in the magnetisation of bars of the same metals, there exists a remarkable analogy, which, however, seems to break down in the case of cobalt. According to these experiments (which, I may mention, were carried out under Sir William Thomson's direction by my brother, Mr. Thomas Gray, and myself), the effect of the application of longitudinal pull to a bar of iron, while under the influence of inductive force tending to produce longitndinal magnetisation, is, for forces lower than a certain critical value, called from the Italian experimenter who first observed it, the Villari Critical Value, to increase, and of the removal of pull, to diminish, the inductive magnetisation. When the magnetising force exceeded the critical value, these effects changed sign, and tended to a constant value as the magnetising force was increased.

Again, the effect of transverse pull, produced by means of hydrostatic pressure in an iron tube, is, when applied, to diminish the longitudinal magnetisation, and when removed, to increase it. We see, then, from Joule's result, confirmed by 